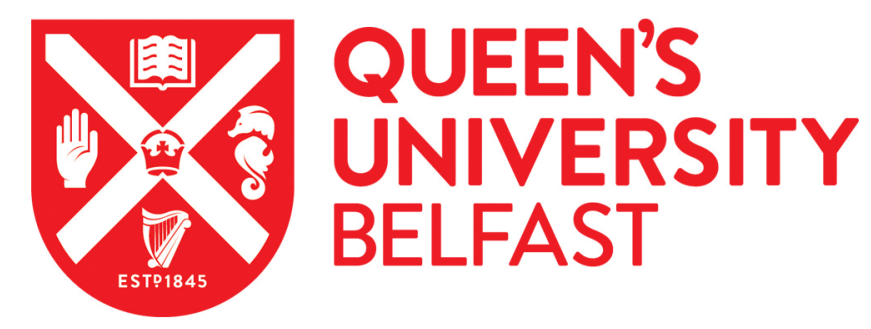

\title{
Maintaining a grasp on reality - Is our validation and design effort focused in the same direction?
}

Price, M., \& Murphy, A. (2016). Maintaining a grasp on reality - Is our validation and design effort focused in the same direction? Journal of Strain Analysis for Engineering Design, (Special Issue), 72-89.

https://doi.org/10.1177/0309324715583168

Published in:

Journal of Strain Analysis for Engineering Design

Document Version:

Peer reviewed version

Queen's University Belfast - Research Portal:

Link to publication record in Queen's University Belfast Research Portal

Publisher rights

(C) 2015 IMechE

\section{General rights}

Copyright for the publications made accessible via the Queen's University Belfast Research Portal is retained by the author(s) and / or other copyright owners and it is a condition of accessing these publications that users recognise and abide by the legal requirements associated with these rights.

Take down policy

The Research Portal is Queen's institutional repository that provides access to Queen's research output. Every effort has been made to ensure that content in the Research Portal does not infringe any person's rights, or applicable UK laws. If you discover content in the Research Portal that you believe breaches copyright or violates any law, please contact openaccess@qub.ac.uk. 


\title{
MAINTAINING A GRASP ON REALITY - IS OUR VALIDATION AND DESIGN EFFORT FOCUSED IN THE SAME DIRECTION?
}

\author{
Mark Price*, Adrian Murphy \\ School of Mechanical and Aerospace Engineering, Queen's University Belfast \\ *Corresponding author: Tel.: +4428 9097 4178; E-mail: m.price@qub.ac.uk
}

\section{ABSTRACT}

This paper examines the influence on the engineering design process of the primary objective of validation, whether it is proving a model, a technology or a product. Through the examination of a number of stiffened panel case studies, the relationships between simulation, validation, design and the final product are established and discussed. The work demonstrates the complex interactions between the original (or anticipated) design model, the analysis model, the validation activities and the product in service. The outcome shows clearly some unintended consequences. High fidelity validation test simulations require a different set of detailed parameters to accurately capture behaviour. By doing so there is a divergence from the original CAD model, intrinsically limiting the value of the validation with respect to the product. This work represents a shift from the traditional perspective of encapsulating and controlling errors between simulation and experimental test, to consideration of the wider design-test process. Specifically, reflecting on the implications of how models are built and validated, and the effect on results and understanding of structural behaviour. The paper then, identifies key checkpoints in the design process and how these should be used to update the CAD system parameters for a design. This work strikes at a fundamental challenge in understanding the interaction between design, certification and operation of any complex system.

\section{KEY WORDS}

Model validation, Design validation, Stiffened panels, Finite Element analysis, Design parameters, Design Freedom, Buckling, Post-buckling. 


\subsection{INTRODUCTION}

As design and simulation capability continues to improve, and engineers become ever more reliant on this technology to reduce product development time, the need for validation of models is evident. In seeking to model a system in as much detail as possible, engineers hope to capture reality and so reduce uncertainty in system design and performance. Representation of reality ever more closely, certainly reduces error, and helps match simulation with test; but getting closer to the reality of the test does not imply being closer to the reality of the system in service. This paper examines this complex situation.

There are many varieties of design processes which have evolved through industrial practice in developing new products and systems. Abstract representations of these are typified by Boehm's spiral model of design (Figure 1) [1], or the classic three stage design synthesis diagram from systems engineering (Figure 2) [2]. In all such abstractions verification and validation loom large as pivotal elements demonstrating the quality and performance of the system to the customer's satisfaction. In many industries the ' $V$ ' diagram from systems engineering is the embedded approach to system development and validation. In this, the system is broken down to its smallest component elements for design and development. These smallest elements are tested, these are then integrated into the higher system level, tested again and so on until the whole product is assembled, and tested in its final operational state. The concept is simply that by testing the sub-components that the final integrated system has a better chance of performing to expectations. This building block approach is ingrained in engineering systems development.

Verification or validation of the in-service performance of a new product is clearly the critical question for the customer or certification authorities, and one which has many challenges. Validation via physical testing alone requires large amounts of expensive infrastructure, along with great time and cost [3]. Additionally, it can be difficult and in some cases impossible, e.g. extreme environment applications, to faithfully represent in-service conditions in a structural test programme $[4,5]$. The simulation of structural failure by numerical methods has long been possible [6], and with the appropriate and disciplined use of simulation software the physical behaviour of many scenarios may be accurately modelled. However, potential unknowns or variability in the physical materials and the environment in which they are manufactured and operate suggests that computational methods cannot replace physical testing completely. Nevertheless, with robust, validated procedures numerical predictions for individual applications can be significantly narrowed, and simulation tools demonstrated to have the potential to reduce the amount of experimental tests required to validate a new design, material or process [7-10]. This is exemplified by the SAFESA 
work [11] which defines procedures for capturing, understanding and reducing errors, or mismatches, between the real and model world. More recently this has been used in non-linear analysis to reduce errors in the collapse of stiffened panels [12]. In Campbell et al [12] error sources are classified, including geometric imperfections and boundary/loading conditions, but the work does not address the source of problems arising in the design or manufacturing processes, or their implications on the model geometry. Whilst this, and the wider body of work on material and structural testing demonstrate the ability to represent real conditions in a model, the larger question of the design process and how it influences results remains unanswered.

While validated simulations should therefore continue to form a core element of current engineering practice, the ideal process of creating and validating the performance of a new product is not necessarily appropriate or satisfactory for developing and validating a computational model to represent the in-service behaviour of a product. Thus a significant dichotomy in test requirements particularly exists when a single experimental programme is expected to satisfy both product and model validation.

This article examines and contrasts the validation requirements for: a new product; a new technology for a product, that is to say a new configuration, material or manufacturing process; and a new computational model to predict the in-service structural performance of a product. The platform of discussion is the common transport vehicle structure of stiffened panels, drawing exemplars from the significant body of research on aerospace structures undertaken at Queen's University Belfast over a period of 15 years. Stiffened panels provide a generic structure which is sufficiently complex to provide challenges in simulation and design, but remains sufficiently well understood to allow study across a number of manufacturing and assembly processes.

The goal is thus for the first time to systematically scrutinise and articulate potential systemic weaknesses within current design and validation philosophies used for product development. In drawing out and expressing the current mismatch between design and validation philosophies it is foreseen that greater discussion on the topic may occur, which will lead to future research enabling better alignment of design and validation in product development. It is clear from this work that a model building process with consistent parameters at all levels of the system is needed.

The next section looks at the background to design, analysis and testing process for systems in general, before providing a detailed look at the design of stiffened panels. The subsequent section then examines a number of example case studies, studying stiffened panel behaviour under a variety of conditions. The results from these tests are then discussed in the context of the wider validation 
question, drawing new insights and conclusions with respect to design and analysis systems and processes.

\subsection{BACKGROUND}

Design is typically a highly iterative process in which many disciplines are examined through a spiralling evolution of design detail. Initially highly idealised analysis methods facilitate rapid analysis and design optimisation. However, the vast range of physical behaviours possible cannot be modelled, due to the limited design data and simple structural representations. As the design matures these idealised models used for conceptual design evolve to better represent the physical behaviour of the design and the increasing design data (a cross-sectional area becomes a width and thickness, buckling behaviour may then be considered along with material yielding and so on). Ultimately, high fidelity models at the final design stages are possible, allowing the consideration of complex non-linear and coupled physical behaviours. For simple small products these high fidelity models may represent the complete product structure but for larger and for complex products these models will typically represent critical components or sub-assemblies which require particular attention due to their influence on final product functional performance, safety, reliability, weight, cost etc..

\subsection{TESTING THROUGH THE DESIGN PHASES}

Within the early design phases prototyping and testing are required to assess the performance of a new technology against the established solutions and confirm the ability of the design process to predict performance in service. The performance test is typically drawn from designer experience and will represent what are assumed to be the critical in-service conditions for the product type. This generic testing has the added benefit that previous technology will have been tested under these conditions allowing direct comparison. Such physical validation builds confidence in the new technology, and de-risks the individual design as it is developed.

As the design matures, from concept to final form, the focus of physical testing switches from demonstrating technology, to demonstrating that the final design solution complies with the relevant design codes, or certification requirements. At this stage significantly greater data is available on the design and thus on the in-service loading conditions. However, often the number of external loading cases is vast, for example in the case of an aircraft sometimes beyond $10^{6}$. As it is not possible to test all of these cases some form of down-selection is implemented, usually testing 
the cases with maximum or minimum magnitudes and then using engineering judgment or defined design codes or certification rules for the testing of combinations of loading cases [13].

As noted earlier, certification programmes are typically structured with a building block approach, comprising of coupons, structural details, sub-components and full scale component tests. This style of test programme allows the uncovered understanding of structural behaviour and best performing candidate design, design features or process parameters to flow into the subsequent building blocks. The results of lower level testing may also provide data for the validation or calibration of analysis methods to be used in subsequent design iterations.

The ultimate final product tests are normally expensive, relative to the preceding tests, owing to their scale and complexity. As the purpose of these tests is to prove an individual design and its associated in-service behaviour, the instrumentation and measurement will normally focus on capturing the key performance characteristics which will satisfy the relevant codes or certification obligations. Additional expense in capturing other behaviours or behaviour under other conditions, potentially critical for verifying or validating the design process, but not essential to prove the design are typically excluded on the grounds of both cost and time.

It is worth also discussing the evolution and influence of experimental techniques. Historically, applied force, point deformation and strain data have been the principal experimental measurements. However over recent decades the development of image processing algorithms, digital camera technology (CCDs) and computing power has enabled significant advances in noncontact full-field measurement [14, 15]. This full-field measurement capability has led to the design of novel test procedures [e.g. 15, 16]. Hild and Roux [17] identify the potential of full-field measurements to bridge the gap between experiments and simulations by enabling the direct comparison of displacement and strain. They outline five uses; to assess boundary conditions; to control an experiment using data from full-field measurement, to perform heterogeneous tests on materials or structures, to enable measurement within hostile test environments, or measurement of very sensitive materials; and to develop material models. Full-field measurements may also enable improved and more cost efficient testing, potentially revealing improper or undesirable effects (e.g. misalignments of loading, heterogeneous strain fields or local effects near the loading or boundary condition) [18]. Full-field measurement capability may also relax the requirements associated with specimen geometry and loading conditions [18, 19], allowing the design of experiments in which the conditions are much closer to the in-service conditions [18]. Or through an inverse problem approach defining loads and boundary conditions to match in-service measurements [19]. However, there has been only a slow adoption by industry of full-field 
measurement techniques [20]. One potential cause of the slow adoption, identified by Patterson et al., is the lack of internationally recognized procedures for calibration. Patterson et al. addresses this weakness by demonstrating the development of devices and methodologies to calibrate optical systems for full-field strain measurement [21]. Such work, along with approaches for the assessment of image processing algorithms [e.g. 22] and error control and uncertainty assessment [e.g. 23, 24] pave the way for the widespread adoption of non-contact full-field experimental techniques for industrial testing. A final challenge however resides in the demonstration of the scalability of many techniques from the component level to the product level, and future benefits of full-field methods in efficiently examining large volumes of potential in-service loading conditions.

\subsection{PRODUCT EXEMPLAR - STIFFENED PANELS}

Stiffened panels are used in the design of aircraft and space vehicle wings and fuselages, railway carriages, ship hulls etc.. Over recent decades the materials and manufacturing processes use to produce transport vehicle stiffened panels has evolved significantly. Starting with aluminium and mechanical fastening (riveting) in aerospace, and steel and welding (Metal and Tungsten Inert Gas (MIG \& TIG) welding) for marine and rail; the drive for cheaper, lighter and more fuel efficient vehicles as introduced new materials and assembly processes which can reduce the manufacturing cost and assembled weight of panels. Aerospace panels are now machined from single near-net size blanks or welded using laser beam or friction stir welding and combinations of advanced aluminiumalloys, or produced using carbon fibre composite materials with which the stiffeners are again integrally manufactured with the skin. In marine and rail aluminium-alloys or composite materials have replaced the traditional steels, reducing weight, and again advanced manufacturing processes have introduced automation and reduced assembly time and cost. Given these recent developments stiffened panels are thus an ideal platform to discuss validation with respect to analysis models, new technologies and new products. Exploration of the idealisation and modelling challenges will be organised on the common themes of Material, Geometry, Boundary Conditions and Initial Conditions, which cover the key characteristics across all engineered products. A summary section will then attempt to generalise shared conclusions from the specific case studies which will hold for other structural components, material types and physical performance criteria.

Stiffened panels consist of an external skin, stiffened by both longitudinal and lateral stiffeners, which stabilise the structure from within. When loaded in shear, compression or bending such thinwalled structures can exhibit structural instabilities at stress levels lower than their material limits, due to an unstable event commonly referred to as buckling [25]. The inclusion of longitudinal and 
lateral stiffeners partitions the structure into smaller units. The stiffeners increase out-of-plane stiffness and with the smaller units produce a more buckling resistant structure. Partitioning with distributed stiffeners can also create a more damage tolerant structure, with the introduction of stiffness changes and or physical breaks in the structure having the potential to retard or stop crack growth. It is however possible to design stiffened panels to have a stable post-buckling response and therefore maximise panel strength to weight ratios by allowing the skin in between stiffeners to buckle in service at defined percentages of the ultimate load [26]. This buckling skin arrangement can offer notable weight savings over non-buckling designs for panels located in non-critical aerodynamic or hydrodynamic areas [27]. Typically, in initial design the panel structure is idealised as a plate with a smeared thickness (for either metallic or composite design) with heuristic or highly idealised loading and strength calculations undertaken [28-29 \& 30-32]. As the design evolves the thickness information is extrapolated again using heuristics to provide an estimate of gross stiffener areas and nominal skin thicknesses. Thus higher fidelity strength analysis can then take place for individual skin and stiffener components [33-35]. Given this increased structural definition Finite Element (FE) global vehicle loading models may be generated. The models are initially highly idealised representations of the global structure, in which the philosophy is to model the structure with sufficient detail to evaluate load paths and load levels [29]. Key in defining the appropriate idealisation is the time available for a design iteration, the time for model creation, the number of load cases, the accuracy required from a single simulation, post-processing requirements and the available computational power. Thus idealisation is only part of a more complex design process trade-off. Even for the examples in this work idealisation is several days' effort. Analysis run-times of minutes are trivial by comparison. The loads obtained from the global loading models are then used to update strength analysis and sizing of individual skin and stiffener components. Iteratively this process of looping 'strength analysis and sizing' with 'loading analysis' is repeated with increasing design detail being added and increasing strength and loading analysis fidelity. Ultimately, with FE models employed to predict strength, all relevant panel detail may be modelled. At each iteration design optimisation refines the local design (thicknesses in metallic panels or stacking sequence in composite panels) using a vast range of potential algorithms [36-40].

\subsection{LESSONS LEARNED IN MODELLING \& TESTING}

From a computational modelling perspective there are four key aspects to consider: 
- Material

- Geometry

- Boundary Conditions \& Loading Conditions

- Initial Conditions

Each of these are considered in turn below.

\subsection{MATERIAL: IDEALISATION \& MODELLING}

Consider the stiffness and strength of a simple small scale specimen under compression loading illustrated in Figure 3 [41]. The figure presents a single test curve and two FE simulation predictions. Both simulated using the same mesh, elements, and solution procedure with the only variation in input the material models. The first model employs the relevant material data from a standard material reference (MIL-HDBK) [42]. The second simulation employs material test data from test coupons taken from the same material batches from which the test specimen was manufactured. The Ramberg-Osgood definition for material stress-strain behaviour was employed to generate full stress-strain relationships [43]. The generated stress-strain relationships were then incorporated into the FE analysis models using the 'classical metal plasticity' constitutive theory available within the ABAQUS material library [44].

The simulation with reference material data under predicted specimen global collapse by $8.2 \%$ and the simulation with material coupon data over predicted the specimen performance by $0.6 \%$. Clearly, given that the material data was the only variation between the models, the source of material properties has a major influence on simulation prediction. The question then arises as to the required source and fidelity of material data. If the requirement of the test was to validate the computational analysis this could be best achieved as a deterministic analysis with actual specimen material properties from the same material batch. However considering product design, unless such data would be used within 'Condition of Supply' requirements a different approach would be required, considering material variability. For validating a new technology, and particularly when benchmarking against previous or other technologies the potential influence of batch material properties must be captured to be understood. Table 1 summarises the particular requirements for each validation objective (for a model, for a technology, for a product).

A notable feature of the stiffness data in Figure 3 is the discrepancy in post-buckling stiffness between the test specimen and the FE predictions. The cause of this discrepancy was ultimately determined to relate to the specimen test boundary conditions. Thus we will refer back to this test when considering model loading and boundary conditions in Section 3.3. 


\subsection{GEOMETRY: IDEALISATION \& MODELLING}

Let us consider the example of the idealisation of skin-stiffener joints within a welded stiffened panel [45-46]. In this example the focus is a single stiffener test specimen, Figure 4, in which the skin and stiffener are lap welded by friction stir welding. The same simulation software is used as in the previous case study (ABAQUS). Three specimens, of length $215.4 \mathrm{~mm}$, were tested to failure under compression loading. No skin edge support members were used in these tests. Three joint idealisations were considered, Figure 4. In Method 1 the specimen is assumed to act as an integral structure with all nodes on the stiffener flange connected to the corresponding skin nodes. In Method 2 the weld joint is explicitly modelled, with nodes in the skin and stiffener weld area connected with rigid links. Method 2 does not model the contact condition between the unwelded skin and stiffener flange and therefore within the post-buckling domain the skin and flange elements may penetrate each other. Method 3 models the weld plus the skin and flange interface contact conditions. This is accomplished with the remaining nodes at the interface linked using uni-axial gap elements.

All three simulations predict pre-buckling stiffness which correlates well with the experimental data. Method 1 predicts an overly stiff post-buckling stiffness and ultimately over predicts the specimen failure load $(+9.2 \%)$. Method 2 under predicts the post-buckling stiffness and failure load $(-6.5 \%)$. Method 3 most accurately represents the post-buckling stiffness and failure load $(+1.1 \%)$. The choice of idealisation philosophy is therefore highly dependent on the anticipated behaviour of the structure, as the model idealisation must be capable of accurately representing the critical structural characteristics. In order to represent the buckling failure modes of a stiffened panel the structure is most appropriately idealised as an assemblage of shell elements, with the skin, stiffener web and stiffener flanges represented as a series of inter-connected plates [47]. Thus a key component of the geometric idealisation is the representation of the boundaries between the various structural components. Consequently, to validate a computational model, this could best be achieved modelling actual specimen joint geometry. Conversely, if the target is the validation of a new technology, simulations and testing need to be used to understand the influence of the processing window on joint geometry and the resultant influence on structural strength. Considering product design, a non-deterministic approach would be required considering the tolerances of the productionised welding process. Table 2 summarises the joint geometry requirements for each validation objective (for a model, for a technology, for a product).

\subsection{BOUNDARY CONDITIONS: IDEALISATION \& MODELLING}


In Section 3.1 a notable discrepancy was noted in the post-buckling stiffness between the physical test data and the simulations. Figure 5 illustrates the experimental setup for the test, detailing the applied skin edge members. The cause of this discrepancy was the tendency of the edge support bars to separate as skin buckling occurred, with alternate buckles prising the bars apart. This effect essentially reduced the degree of restraint on the edges of the test specimen skin, thus increasing the extent of the skin buckling and hence reducing the post buckling stiffness. However, in the simulation the edge support assemblies were not physically modelled, only their design-intent of restraining the out-of-plane translation of the skin zones within the supports. Therefore, in the postbuckling range the experimental and computational curves diverge, Figure 3, Section 3.1

Even with well-designed support members, specimen manufacturing tolerances can introduce uncertainty as to the true applied edge conditions. Small variations in different specimen distortion shapes may induce differing edge conditions with the same set of support members and specimen design [4]. Thus test specimen edge support design typically aims to represent a condition in which there may be a minimum of uncertainty, for example a free edge or clamped edge. This philosophy however can direct the testing and associated simulations away from representing in-service conditions.

Considering loading, here great divergence is possible between the in-service event or events and the practicalities of testing a portion of a structure. Considering the simple form of loading for the previous case studies, uniform compression, this firstly assumes that loading will act alone and secondly assumes that this loading will be uniform in the particular in-service event. Both assumptions may be true but more likely the engineers can justify that the loading simplifications are conservative and recreate a 'worst case scenario', for example it may be assumed that lateral loading will always be tensile due to internal pressure. With regards uniform loading this can result in restrictions on the specimen design - even though a large panel specimen with multiple stiffeners may be tested the specimen only represents a single stiffener design within a repeating larger structure. As such the design of the test specimen is restricted and may not represent the product design. Such difficulty suggests that full system testing is a solution, however setting aside issues of time and cost, identifying the performance and loading of individual sub-components within a full system test is very challenging and in cases impossible, for example locally at the load introduction points.

More generally, loading must be introduced within an area of the product or specimen which is naturally reinforced or must be reinforced. For either a full product test or a component test this preparation will necessitate additional processing, bonding, casting, fastener installation, which can 
induce initial states of stress not present in a final product. For static testing loading is applied monotonically and in displacement or load -control. Testing in displacement-control is normally considered safer than in load-control because post failure behaviour is better controlled, however this can deviate from true in-service loading. The use of monotonic loading, displacement or load control will also impact on which simulation approach is most appropriate, potentially creating a further disconnect. Considering model loading and boundary conditions, Table 3 summarises the particular requirements for each validation objective (for a model, for a technology, for a product).

\subsection{INITIAL CONDITIONS: IDEALISATION \& MODELLING}

Initial conditions such as geometric imperfections and or residual stresses can have a significant influence on the strength of stiffened panels [48-50]. Consider the static stiffness and strength of a riveted specimen with multiple lateral and longitudinal stiffeners, Figure 6 [26]. The figure presents test results and a series of simulation predictions with each simulation representing a different magnitude of initial geometric imperfection. The peak magnitudes of the imperfections in the simulations are labelled $A$ in Figure 6 . While the pre and early post buckling structural responses are almost identical for all simulation results, the predicted load carrying capacity is highly sensitive (16\% between the baseline with no imperfection, and the maximum imperfection). This is due to the fact that as the applied load is increased, with the presence of these geometric imperfections, corresponding overall out-of-plane deflections develop thus increasing the compressive stresses in the stiffener and promoting specimen failure.

Considering more complex initial conditions Figure 7 presents experimental and computational stiffness and strength data for a friction stir welded stiffened panel design with multiple lateral and longitudinal stiffeners [51]. In this case two initial imperfection states are presented, both representing different zones of a welding processing window. Both imperfections consider variation in the width of the effective weld joint, the location of the effective weld joint centre, the effective strength of the weld degraded material, the width of the degraded material and the magnitude of welding induced residual stress. Both simulations predict the same axial stiffness up to initial skin buckling. Beyond this region the curves diverge. In Figure 7 the small differences in buckling behaviour can be observed, these variations result in the $8 \%$ difference in the predicted specimen collapse load.

Reflecting on the above results, it is possible through such coupled experimental testing and simulation to understand the influence of individual initial conditions on stiffness and strength. In each case the initial conditions result from the selected panel assembly processes, riveting and 
welding, and thus understanding of the influence of manufacturing processes on stiffness and strength can be developed. This is particularly important with respect to initial design and the fact that the definition of local joint features or the global configuration may directly influence manufacturing resultant initial conditions. Moreover, structural optimisation without the consideration of such manufacturing induced initial conditions and the design features which effect their form and magnitude may not result in a design which performs as required.

Consider Figure 8 which presents the output of a design study for a stiffened panel design series considering panel assembly via laser beam welding [52]. The first design analysis considers the design of a series of panels assuming no welding induced initial conditions (labelled in the figure as 'zero weld effect design line'). Having sized the panels assuming no welding induced initial conditions the static performance of each design in the series is then reanalysed assuming severe welding induced initial conditions. Examining the calculated design lines there is a significant drop in the load carrying capacity when the sized designs are reanalysed assuming the complete complement of welding induced initial conditions. The greatest drop in load carrying capacity is $18.5 \%$. With such differences between target and calculated performance it is clearly important to consider the initial conditions within the sizing process. Figure 8 also presents a further design study line when the welding induced initial conditions are modelled within the sizing process. It can be seen that it is possible to create panel designs which match the zero welding induced initial conditions performance when the optimisation process considers the critical structural behaviour and most relevant design parameters. Further studies have also identified that the location of assembly joints is also important to the initial conditions and panel static strength [53].

The process of validation, whether for a model, a technology, or a product must therefore be allowed to iteratively feed the higher-level design activities with the most appropriate design freedoms for optimisation. Table 4 summarises the particular requirements for each validation objective considering model initial conditions.

\subsection{DISCUSSION: IMPLICATIONS FOR DESIGN MODELS AND DESIGN FREEDOMS}

The exemplars summarised in Section 3.0 clearly demonstrate that the process of design, analysis and test, all brought together with a building block approach, gradually adds knowledge about the structure and its performance. It is interesting to consider this from a higher level perspective as to what is happening in terms of the detailed geometry, design parameters and design freedoms. In this discussion three key lessons emerge as guidance for future validation systems. 
The studies all focused on stiffened panels under compression loading. The panels are thin, and buckling is a key failure mode. What emerges from these studies is that the conceptual model for all cases is the same: a thin sheet with stiffening elements. The panels had different manufacturing processes. In each case this adds some detail to the concept with additional geometric parameters appearing to define the regions and components. There is therefore a divergence in the geometry at this decision point on the process to be used. But each additional parameter adds a design freedom, another dimension to modify. To illustrate this point Figure 9 demonstrates the evolution of design parameters as manufacturing decisions are taken in the design evolution of an aircraft fuselage. This is a critical observation as any optimisation is now being set off on a different path. The concept remains the same, but the set of parameters that describe it is different in each case. The manufacturing process has therefore specified the design freedoms.

The analysis models now add another layer of complexity. The design geometry is idealised to allow the most efficient and accurate representation of the behaviour to be captured. The design is now effectively represented by another set of parameters. In addition to the geometric approximations, material property approximations are also added. This may be as simple as the Elastic Modulus, or a derived attribute such as inertia (second moment of area) or stiffness. It allows for many variations. As in the case of manufacturing processes the idealisation has now effectively represented the concept with another set of parameters.

What is clear is that the choice of manufacturing process and the choice of idealisation define the design freedom for each concept. Thus Figure 10 shows two methods of parameterising a stiffened panel, reflecting two different manufacturing processes. The top parameterisation could represent the case where the three regions in dashed lines are to be machined out of a block of material. The bottom parameterisation could represent where two stiffeners are attached to a panel skin. In their current state both parameterisations represent the same panel geometry, however selecting the bottom parameterisation constrains the skin thickness to be constant, whereas machining allows $D_{1}$, $D_{2}$ and $D_{3}$ to vary in magnitude. Of great significance is the fact that each different parameterisation will produce a unique design optimum.

The question is how to capture and control the evolution of the parameters as the design progresses. It is clear that the geometry within the CAD systems should be ideally the same as that in the analysis model. In investigating this a surprising problem arises. In an effort to provide flexibility CAD systems allow many ways to construct geometry. Figure 11 shows a number of ways to create a square. The result of this is that even a simple shape may have a different geometric representation from the designer's intent. Therefore, there is an opportunity for any analysis or 
simulation to be conducted using a different set of parameters, leading to different results and conclusions. The example of figure 10 could therefore lead to a large number of parametric versions. Thus another view, and potential error source has been added to the process. From a geometric modelling perspective this has never been a problem as the underlying representation was not a major consideration. Further, historically analysis models were traditionally built completely outside the geometric modelling system and were therefore not intended to be so tightly linked. However, the proceeding exemplars and discussion clearly exposes the need for a common representation of the design in all these segments of the process so that at each point the same parameter set can be used. This is the first lesson:

Lesson 1: A new integrated approach to design and analysis modelling is needed to ensure consistency in the parameter sets used in all phases of the design and validation process.

While it could be argued that a fully detailed solid model with complete computational capability would resolve this, such is unlikely, and is perhaps not even possible. One pragmatic approach to account for the highlighted disconnects in the current model building process is the concept of "dimensional addition and detail insertion" [54-55]. Such approaches define how a CAD model can be built to accommodate an evolving design, maintaining designer intent and allowing robust and efficient links between the design and analysis models. These modelling philosophies have shown promise in the design and simulation of reasonably complex assemblies but have yet to be fully explored in the context of the more complex integrated manufacturing systems environment exposed here as being the real challenge to validation.

While such an approach may help to reduce errors and improve confidence in validation results and their implications for a design there are other interesting observations which have arisen from considering this broad range of studies. The drive for each study was to assess a particular material or technology influence on the design and manufacture of a product. Hence the four aspects were studied (Material, Geometry, Boundary Conditions \& Loading Conditions and Initial Conditions) to achieve the most complete view possible. From the validation perspective this raises some interesting questions. It can be seen that validation of a given tightly constrained scenario is achievable, and therefore analysis and simulation can aid the design definition close to the validated configuration [56,57]. But what of trying to consider a wider range of solutions, and having a more open design process that allows significant variation from the starting concept? It has been demonstrated that each idealisation and manufacturing process introduces different freedoms. Similarly the real geometry and real in-service conditions introduce further freedoms and parameters. So, while the validation gives some confidence that what was tested behaved as 
predicted, it leaves the global behaviour uncertain. If the aim of validation is to give confidence in predictions and help make better designs then this uncertainty gap must still be understood and eventually bridged. Here non-deterministic approaches [58] offer great potential to understand the influence of uncertainty in simulations and thereby reduce over conservatism in design, minimize variation sensitivity (robust design), augment and guide validation testing (simulation based certification). However, ultimately industry currently relies on successful full scale tests and key assumptions backed up by further analysis to provide confidence that the system will not fail in unexpected ways. Until the complete system can be tested, and measured, this gap will remain a challenge.

If the perspective shifts to the design, technology and product view then it is clear that validation for each is focused on different questions. Table 5 illustrates the key elements relevant to each, as summarised and rephrased from the points in Tables 1-4. It then becomes clear that any validation is limited to the domain that it emerged from. While perturbations on geometry, material etc. can be understood, large changes or wider questions render the validation uncertain and reduce confidence in its conclusions. For example, a detailed validation of the behaviour of a welded stiffened panel may give confidence in basic load carrying capacity. However, if the process of assembling this panel within a larger structure alters the panel's initial conditions then confidence from the validation process is also altered. This is the second lesson:

Lesson 2: Design and validation effort are often focused in different directions, varying between basic understanding of a configuration, detailed understanding of a manufacturing technology or process, and demonstrating product performance for certification.

When it comes to validation at the product level many complex systems have so many variations in operational scenarios and loads that it may even be impossible to obtain results for all of them. In this case, the validation becomes focused on a few key load cases and scenarios. As a structural analogy this is akin to a single strain gauge in a large structure. It gives a sample point to compare with. It also therefore leaves much to be explored to increase understanding of that product.

This is an interesting point to come to. In the early days of simulation, single point comparisons with testing via a few well-placed strain gauges was the state-of-the-art. Simulation was limited to analytical and semi-empirical solutions and linear static FE analysis. Figure 12 shows a schematic timeline of the development of simulation capability, illustrating the progression from simple material models to non-linear geometry and subsequently more sophisticated boundary conditions (such as contact) and finally the inclusion of initial conditions. Similarly validation has progressed 
now to full field strain measurement, which is still developing apace. Validation development has therefore followed this trend as capability as developed, moving along with the simulation capability for component level. However, scalability from the component level to a product under in-service loading is currently more practicable for the simulation developments than for the experimental developments. But both computational and full field strain measurement capability remain well below that needed for complete product validation. This is the third key lesson from the work:

Lesson 3: A step change in validation processes and measurement capability is needed to allow fuller measurement of the product in its operational environment.

\subsection{CONCLUSIONS}

The development of simulation and validation technologies have significantly enhanced capability to understand the behaviour of designs, and have allowed very detailed validation of structural configurations and the influence of manufacturing processes on components. It is clearly possible to achieve a high degree of accuracy by capturing the material, geometry, boundary conditions and initial conditions and using these with an appropriately idealised model. The review and reassessment of a large number of experimental studies on stiffened panels, and the corresponding computational analysis, has revealed new insights into the limits of validation capability and the gaps between simulation, validation and design. While sophisticated analysis and validation processes give great confidence in tightly defined scenarios for specific purposes in understanding component and technology behaviour, new CAD modelling procedures are needed in combination with advances in simulation and test capability to allow validation of fully defined products in service. Until now, development of validation technology has progressed through studies on material, geometry, boundary conditions and initial conditions, following the development of computational technology. While it has seemed for a while that it should be possible to validate any model prediction by having as much detail as possible in the model and carefully matching this to the test, it has become clear that attempts to validate detailed design models of real products in service has exposed gaps in the procedure from design to analysis to validation. Therefore, to move into the next era, Table 6, and to have better understanding of the final product in service, full field measurement and computational capability has to move to the product level with new design procedures that both maintain consistency between design, analysis and validation models; and allow evolution of the parameter sets to match the manufacturing technology used to produce the final product. In addressing the original question as in the title of this paper it is clear that validation 
and design effort is focused in different directions, but the three key lessons identified herein offer a path to the next level in full product validation.

\subsection{REFERENCES}

[1] B Boehm. A Spiral Model of Software Development and Enhancement. IEEE Computer, IEEE, 21(5):61-72, May 1988

[2] Systems Engineering Fundamentals. Defense Acquisition University Press, 2001

[3] M Price, A Murphy, C Goniallez-Murillo, J Butterfield, R McCool. A Virtual Test System Integrating Materials and Manufacturing to aid Design choices. $10^{\text {th }}$ AIAA Aviation Technology, Integration, and Operations (ATIO) Conference, 13-15 October, Fort Worth, Texas, USA, 2010. AIAA-2010-9071

[4] A Murphy, M Price, A Gibson. Toward Virtual Testing of Airframe Stiffened Panels. Royal Aeronautical Society - Virtual Testing Conference, Hamilton Place, London. 25-26 Oct. 2006.

[5] KJ Bathe. On reliable finite element methods for extreme loading conditions. A Ibrahimbegovic, I Kozar (Eds.), Extreme man-made and natural hazards in dynamics of structures, Springer-Verlag, 2007, pp. 71-102.

[6] O C Zienkiewicz, Y K Cheung. The Finite Element Method in Engineering Science. McGraw-Hill, London, 1967.

[7] P Linde, A Schulz, W Rust. Influence of modelling and solution methods on the FE-simulation of the post-buckling behaviour of stiffened aircraft fuselage panels. Composite Structures, Volume 73, Issue 2, 2006, pp. 229-236.

[8] C Hühne, A-K Zerbst, G Kuhlmann, C Steenbock, R Rolfes. Progressive damage analysis of composite bolted joints with liquid shim layers using constant and continuous degradation models. Composite Structures, Volume 92, Issue 2, 2010, pp. 189-200.

[9] M I Okereke, A I Akpoyomare, M S Bingley. Virtual testing of advanced composites, cellular materials and biomaterials: A review, Composites Part B: Engineering, Volume 60, 2014, pp. 637-662.

[10] H Guo, C Bastien, M Blundell, G Wood. Development of a detailed aircraft tyre finite element model for safety assessment. Materials \& Design, Volume 53, 2014, pp. 902-909

[11] A Morris, R Vignjevic, Consistent Finite element structural analysis and error-control, Computer Methods in Applied Mechanics and Engineering, Volume 140, Issues 1-2, 1997, Pages 87-108

[12] J Campbell, L Heatey, R Vignjevic, Non-linear idealisation error analysis of a metallic stiffened panel loaded in compression, Thin-Walled Structures, Volume 54, 2012, Pages 44-53 
[13] S McGuinness, CG Armstrong, A Murphy, J Barron and M Hockenhull. Improving aircraft stress-loads evaluation and optimization procedures. $2^{\text {nd }}$ Aircraft Structural Design Conference, London, October 2010

[14] M. Grédiac. The use of full-field measurement methods in composite material characterization: interest and limitations. Composites Part A: Applied Science and Manufacturing, Volume 35, Issues 7-8, July 2004, Pages 751-761

[15] S. Avril, M. Bonnet, A.-S. Bretelle, M. Grédiac, F. Hild, P. lenny, F. Latourte, D. Lemosse, S. Pagano, E. Pagnacco, F. Pierron. Overview of identification methods of mechanical parameters based on full-field measurements. Exp. Mech. Vol. 48, 2008, 381-402

[16] M. Rossi, F. Pierron. On the use of simulated experiments in designing tests for material characterization from full-field measurements. International Journal of Solids and Structures, Volume 49, Issues 3-4, February 2012, Pages 420-435

[17] Hild, F. and Roux, S. Digital Image Correlation: from Displacement Measurement to Identification of Elastic Properties - a Review. Strain, Vol. 42, 2006, pp. 69-80

[18] Michel Grédiac, The use of full-field measurement methods in composite material characterization: interest and limitations, Composites Part A: Applied Science and Manufacturing, Volume 35, Issues 7-8, July 2004, Pages 751-761

[19] S. Padmanabhan, J. P. Hubner, A. V. Kumar, P. G. Ifju. Load and Boundary Condition Calibration Using Full-field Strain Measurement. Experimental Mechanics, October 2006, Volume 46, Issue 5, pp 569-578

[20] E.A. Patterson, E. Hack, P. Brailly, R.L. Burguete, Q. Saleem, T. Siebert, R.A. Tomlinson, M.P. Whelan. Calibration and evaluation of optical systems for full-field strain measurement. Optics and Lasers in Engineering, Vol. 45, Issue 5, May 2007, Pages 550-564

[21] E.A. Patterson, E. Hack, P. Brailly, R.L. Burguete, Q. Saleem, T. Siebert, R.A. Tomlinson, M.P. Whelan. Calibration and evaluation of optical systems for full-field strain measurement. Optics and Lasers in Engineering, Vol. 45, Issue 5, May 2007, Pages 550-564 plus SPOTS Standard Part $1 \& 2$, Calibration and assessments of optical strain measurements, www.opticalstrain.org, 2006

[22] M. Bornert, F. Brémand, P. Doumalin, J.-C. Dupré, M. Fazzini, M. Grédiac, F. Hild, S. Mistou, J. Molimard, J.-J. Orteu, L. Robert, Y. Surrel, P. Vacher, B. Wattrisse. Assessment of Digital Image Correlation Measurement Errors: Methodology and Results. Experimental Mechanics, June 2009, Volume 49, Issue 3, pp 353-370 
[23] M. Fazzini, S. Mistou, O. Dalverny, L. Robert, Study of image characteristics on digital image correlation error assessment, Optics and Lasers in Engineering, Volume 48, Issue 3, March 2010, Pages 335-339

[24] R. Gras, H. Leclerc, F. Hild, S. Roux, J. Schneider, Identification of a set of macroscopic elastic parameters in a 3D woven composite: Uncertainty analysis and regularization, International Journal of Solids and Structures, Volume 55, 1 March 2015, Pages 2-16

[25] P S Bulson. The stability of flat plates, 1st edition, Chatto \& Windus, London, 1970.

[26] C Lynch, A Murphy, M Price, A Gibson. The Computational Post Buckling Analysis Of Fuselage Stiffened Panels Loaded In Compression. Thin-Walled Structures, Volume 42, Issue 10, 2004, pp. $1445-1464$.

[27] R McCune, A Murphy, M Price and J Butterfield. The influence of Friction Stir Welding process idealisation on residual stress and distortion predictions for future airframe assembly simulations. Journal of Manufacturing Science and Engineering, June 2012, Volume 134, Issue 3, pp 031011.

[28] E F Bruhn. Analysis and Design of Flight Vehicle Structures. 1st edition, Tri-State Offset Company, 1973.

[29] A Murphy, M Price, A Gibson, CG Armstrong. Efficient Non-Linear Idealisation of Aircraft Fuselage Panels in Compression. Finite Elements in Analysis and Design. Volume 40, Issue 1314 2004, pp. 1977-1993.

[30] Z. Gürdal, G. Gendron, Optimal design of geodesically stiffened composite cylindrical shells, Composites Engineering, Volume 3, Issue 12, 1993, Pages 1131-1147

[31] N. Jaunky, N.F. Knight Jr, D.R. Ambur. Formulation of an improved smeared stiffener theory for buckling analysis of grid-stiffened composite panels. Composites Part B: Engineering, Volume 27, Issue 5, 1996, Pages 519-526

[32] Eyassu Wodesenbet, Samuel Kidane, Su-Seng Pang, Optimization for buckling loads of grid stiffened composite panels, Composite Structures, Volume 60, Issue 2, May 2003, Pages 159169

[33] NASA Astronautics Structures Manual, Vol. 3. Washington, US: NASA; 1961.

[34] ESDU Structures Sub-Series. Engineering Sciences Data Units. London: ESDU International Ltd; 1965.

[35] Structural use of aluminium, Part 1: Code of practice for design, BS 8118. British Standard Institution; 1991.

[36]B.P. Kristinsdottir, Z.B Zabinsky, M.E. Tuttle, S. Neogi. Optimal design of large composite panels with varying loads. Composite Structures, Vol. 51, 2001, pp. 93, 102.

[37]M. Özakça, N. Tayşi, F. Kolcu, Buckling optimization of variable thickness prismatic folded plates, Thin-Walled Structures, Volume 41, Issue 8, August 2003, Pages 711-730 
[38]O. Seresta, Z. Gurdal, D. Adams, L. Watson. Optimal design of composite wing structures with blended laminates. Composites: Part B, Vol. 38, 2007, pp. 469-480

[39]J. E. Herencia, R. T. Haftka, P. M. Weaver, and M. I. Friswell. Lay-Up Optimization of Composite Stiffened Panels Using Linear Approximations in Lamination Space. AIAA Journal, Vol. 46, No. 9, 2008, pp. 2387-2391

[40]J.F. Caseiro, R.A.F. Valente, A. Andrade-Campos, J.W. Yoon. On the elasto-plastic buckling of Integrally Stiffened Panels (ISP) joined by Friction Stir Welding (FSW): Numerical simulation and optimization algorithms. International Journal of Mechanical Sciences, Volume 76, November 2013, Pages 49-59

[41] C Lynch, S G Sterling. A Finite Element Study of the Post-Buckling Behaviour of a Flat Stiffened Panel. $21^{\text {st }}$ ICAS Congress, Melbourne Australia, ICAS-98-7,7,3, 1998.

[42] MIL-HDBK-5J, Department of Defence Handbook: Metallic Materials and Elements for Aerospace Vehicle Structures, March 2006.

[43] Ramberg W, Osgood W R. Description of stress-strain curves by three parameters, NACA-TN902, NACA, 1943

[44] ABAQUS user manual, Version 6.13, HKS, USA

[45] A Murphy, F Lynch, M Price, P Wang. The Static Strength Analysis of Friction Stir Welded Stiffened Panels for Primary Fuselage Structure. ICAS-2004-5.6.3, 24th International Congress of the Aeronautical Sciences (ICAS), Yokohama, Japan, 2004

[46] A Murphy, M Price, R Curran, P Wang. The Integration of Strength and Process Modeling of Friction-Stir-Welded Fuselage Panels. AIAA Journal of Aerospace Computing, Information, and Communication, Volume 3, Issue 4, pp. 159-176, April 2006

[47] Domb M M, Elliott W G, Leigh B R. Modelling of stiffener Crippling Phenomena Using Finite Element Analysis. Canadian Aeronautics and Space Journal, Volume. 44, No. 4, pp 256-262, 1998.

[48] Stroud WJ, Krishnamurthy T, Sykes NP, Elishako I. Effect of bow-type initial imperfection on reliability of minimum-weight, stiffened structural panels, NASA TP-3263. Washington: National Aeronautics and Space Administration; 1993.

[49] Hilburger MW, Nemeth MP, Starnes JH. Shell buckling design criteria based on manufacturing imperfection signatures. AIAA Journal 2006;44(3).

[50] Widener, C, Tweedy, B, and Burford, D. Path independence of allowables based friction stir butt welds. 7th AIAA Aviation Technology, Integration and Operations Conference (ATIO), AIAA 2007-7864, Belfast, Northern Ireland, 2007. 
[51] A Murphy, T Ekmekyapar, K Poston, G Moore, M Elliott and M Özakça. Static Strength Performance of Friction Stir Welded Aircraft Stiffened Panels. Proceedings of the Institution of Mechanical Engineers, Part G, Journal of Aerospace Engineering, Volume 228, Issue 2, 2014, pp. 178-192.

[52] R Wilson, A Murphy, MA Price and C Glazebrook. A Preliminary Structural Design Procedure for Laser Beam Welded Airframe Stiffened Panels, Thin-Walled Structures, 2012, Volume 55, pp. 37-50.

[53] A Murphy, T Ekmekyapar, D Quinn, M Özakça, K Poston, G Moore and J Niblock. The Influence of Assembly Friction Stir Weld Location on Wing Panel Static Strength. Thin-Walled Structures, Volume 76, 2014, pp. 56-64

[54] M A Price, T T Robinson, D Soban, A Murphy, C G Armstrong, R McConnell, R Roy. Maintaining design intent for aircraft manufacture. CIRP Annals - Manufacturing Technology, Volume 62, Issue 1, 2013, pp. 99-102.

[55] M Price, S Raghunathan, R Curran. An integrated systems engineering approach to aircraft design. Progress in Aerospace Sciences, Volume 42, Issue 4, 2006, pp. 331-376.

[56] A Murphy, F Lynch, M Price, A Gibson, A Modified stiffened panel analysis methods for laser beam and friction stir welded aircraft panels. Proceedings of the Institution of Mechanical Engineers, Part G: Journal of Aerospace Engineering. Volume 220, 4, 2006: pp. 267-278

[57] R McCool, A Murphy, R Wilson, Z Jiang, M Price, J Butterfield,. P Hornsby, Thermoforming carbon fibre-reinforced thermoplastic composites, Proceedings of the Institution of Mechanical Engineers, Part L: Journal of Materials: Design and Applications., Volume 226, 2, Apr 2012, pp. 91-102

[58] I. Elishakoff, Y.L., J.H. Starnes. Non-Classical Problems in the Theory of Elastic Stability. Cambridge University Press, ISBN 052178210 4, 2001 
Table 1 - Material modelling requirements considering simulation, technology and product validation.

\begin{tabular}{|l|l|}
\hline \multicolumn{2}{|l|}{ MATERIAL MODELS } \\
\hline $\begin{array}{l}\text { Computational model } \\
\text { verification / validation }\end{array}$ & Deterministic material data representing the test specimen. \\
\hline $\begin{array}{l}\text { Technology } \\
\text { verification / validation }\end{array}$ & $\begin{array}{l}\text { Modelling with material variation will enable understanding of the } \\
\text { influence of material property variation on technology and on } \\
\text { individual design performance. }\end{array}$ \\
\hline $\begin{array}{l}\text { Product } \\
\text { verification / validation }\end{array}$ & $\begin{array}{l}\text { Modelling with material variation will enable understanding of the } \\
\text { influence of 'Condition of Supply' requirements on product } \\
\text { performance and vice versa. }\end{array}$ \\
\hline
\end{tabular}

Table 2 - Geometric idealisation requirements considering simulation, technology and product validation.

\begin{tabular}{|l|l|}
\hline \multicolumn{2}{|l|}{ GEOMETRIC IDEALISATION - JOINT GEOMETRY } \\
\hline $\begin{array}{l}\text { Computational model } \\
\text { verification / validation }\end{array}$ & $\begin{array}{l}\text { Detailed representation of the specimen joint geometry, including } \\
\text { contact conditions. }\end{array}$ \\
\hline $\begin{array}{l}\text { Technology } \\
\text { verification / validation }\end{array}$ & $\begin{array}{l}\text { Necessary to capture manufacturing process resulting joint geometry, } \\
\text { and represent this to understand the influence of the processing } \\
\text { window on design performance. }\end{array}$ \\
\hline $\begin{array}{l}\text { Product } \\
\text { verification / validation }\end{array}$ & $\begin{array}{l}\text { Modelling with joint geometry variation will enable understanding of } \\
\text { the influence of process capability on product performance and vice } \\
\text { versa. }\end{array}$ \\
\hline
\end{tabular}


Table 3 - Loading and boundary condition requirements considering simulation, technology and product validation.

\begin{tabular}{|l|l|}
\hline \multicolumn{2}{|l|}{ LOADS AND BOUNDARY CONDITIONS } \\
\hline $\begin{array}{l}\text { Computational model } \\
\text { verification / validation }\end{array}$ & $\begin{array}{l}\text { Detailed representation of the test rig induced boundary conditions } \\
\text { and loading. }\end{array}$ \\
\hline $\begin{array}{l}\text { Technology } \\
\text { verification / validation }\end{array}$ & $\begin{array}{l}\text { Detailed representation of the test rig induced boundary conditions } \\
\text { and loading to maximise correlation between test and simulation, } \\
\text { enabling focus on the impact/influence of the technology on individual } \\
\text { specimen performance. }\end{array}$ \\
\hline $\begin{array}{l}\text { Product } \\
\text { verification / validation }\end{array}$ & $\begin{array}{l}\text { Detailed representation of the in-service loading, for a sub-component } \\
\text { representing the in-structure boundary conditions and transmitted } \\
\text { loading. }\end{array}$ \\
\hline
\end{tabular}

Table 4 - Initial condition requirements considering simulation, technology and product validation.

\begin{tabular}{|c|c|c|}
\hline \multicolumn{3}{|l|}{ INITIAL CONDITIONS } \\
\hline $\begin{array}{l}\text { Computational } \\
\text { model verification / } \\
\text { validation }\end{array}$ & $\begin{array}{l}\text { Detailed representation of the specimen } \\
\text { measured initial conditions should be } \\
\text { used for simulation validation studies. }\end{array}$ & \multirow{3}{*}{$\begin{array}{l}\text { The process of validation, } \\
\text { whether for a model, a } \\
\text { technology, or a product must be } \\
\text { allow to iteratively feed the } \\
\text { higher-level design activities with } \\
\text { the most appropriate design } \\
\text { freedoms for optimisation. }\end{array}$} \\
\hline $\begin{array}{l}\text { Technology } \\
\text { verification / } \\
\text { validation }\end{array}$ & $\begin{array}{l}\text { Necessary to capture specimen } \\
\text { manufacturing process resulting initial } \\
\text { conditions, and represent these to } \\
\text { understand the influence of process } \\
\text { variation on strength variation. }\end{array}$ & \\
\hline $\begin{array}{l}\text { Product } \\
\text { verification / } \\
\text { validation }\end{array}$ & $\begin{array}{l}\text { Structural optimisation without the } \\
\text { consideration of initial conditions and } \\
\text { the design features which effect their } \\
\text { form and magnitude may result in } \\
\text { designs which fail to perform as required. }\end{array}$ & \\
\hline
\end{tabular}


Table 5 - Key factors considered for design, technology \& product validation.

\begin{tabular}{|c|c|c|c|c|}
\hline & Material & Geometry & Boundary Conditions & Initial Conditions \\
\hline Design & $\begin{array}{l}\text { Generic Material } \\
\text { Values used to } \\
\text { obtain basic } \\
\text { understanding of } \\
\text { structure. }\end{array}$ & $\begin{array}{l}\text { Variations on potential } \\
\text { shape \& configurations to } \\
\text { understand } \\
\text { perturbations/alternatives } \\
\text { to main configuration }\end{array}$ & $\begin{array}{l}\text { Limited studies with } \\
\text { idealisations and loads } \\
\text { to obtain confidence in } \\
\text { range \& limits }\end{array}$ & $\begin{array}{l}\text { Typically not studied } \\
\text { at this level }\end{array}$ \\
\hline Technology & $\begin{array}{l}\text { Typically use } \\
\text { Material from } \\
\text { Design model - } \\
\text { not the focus of } \\
\text { study at this level }\end{array}$ & $\begin{array}{l}\text { Typically use variation from } \\
\text { Design Model - not the } \\
\text { focus of study at this level }\end{array}$ & $\begin{array}{l}\text { Variations on support } \\
\& \text { clamping conditions } \\
\text { in manufacture to } \\
\text { obtain confidence in } \\
\text { range \& limits }\end{array}$ & $\begin{array}{c}\text { Variations in residual } \\
\text { stresses and } \\
\text { distortions relevant } \\
\text { for the manufacturing } \\
\text { process }\end{array}$ \\
\hline Product & $\begin{array}{c}\text { Require } \\
\text { production } \\
\text { material } \\
\text { information- } \\
\text { percentage } \\
\text { variation in key } \\
\text { material } \\
\text { characteristics }\end{array}$ & $\begin{array}{c}\text { Fixed from design \& } \\
\text { technology studies - not } \\
\text { usually the focus of study at } \\
\text { this level }\end{array}$ & $\begin{array}{l}\text { Boundary conditions } \\
\text { apply for whole } \\
\text { product - } \\
\text { components/systems } \\
\text { from design \& } \\
\text { technology studies } \\
\text { now embedded in } \\
\text { global system }\end{array}$ & $\begin{array}{c}\text { Variation and } \\
\text { combinations typically } \\
\text { too numerous to study } \\
\text { - new conditions arise } \\
\text { from assembly, } \\
\text { disassembly \& } \\
\text { reassembly during } \\
\text { service life. }\end{array}$ \\
\hline
\end{tabular}

Table 6 - Shifting focus to the product/technology phases provides a different perspective on validation aims.

\begin{tabular}{|c|c|c|c|c|}
\hline & Material & Geometry & Boundary Conditions & Initial Conditions \\
\hline Design & \multicolumn{4}{|c|}{$\begin{array}{l}\text { Focus is on understanding basic behaviour of the material and geometry under typical service loading } \\
\qquad \& \text { limit (extreme) loads }\end{array}$} \\
\hline Technology & \multicolumn{4}{|c|}{ Focus is on understanding the influence of the manufacturing process on shape and residual stresses } \\
\hline Product & \multicolumn{4}{|c|}{ Focus shifts to typical service and limit loads of the product } \\
\hline
\end{tabular}




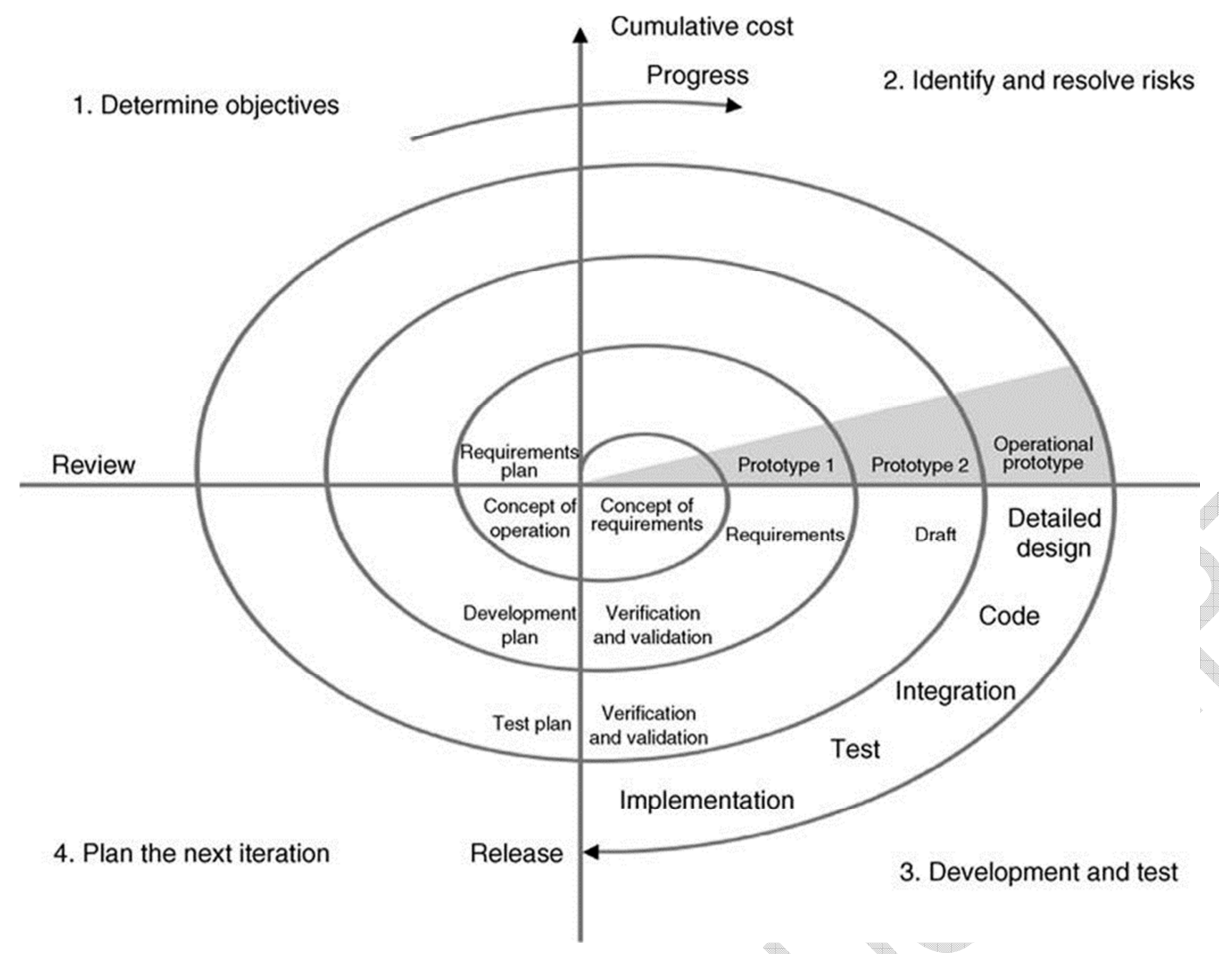

Figure 1 - Boehm's spiral model of design.

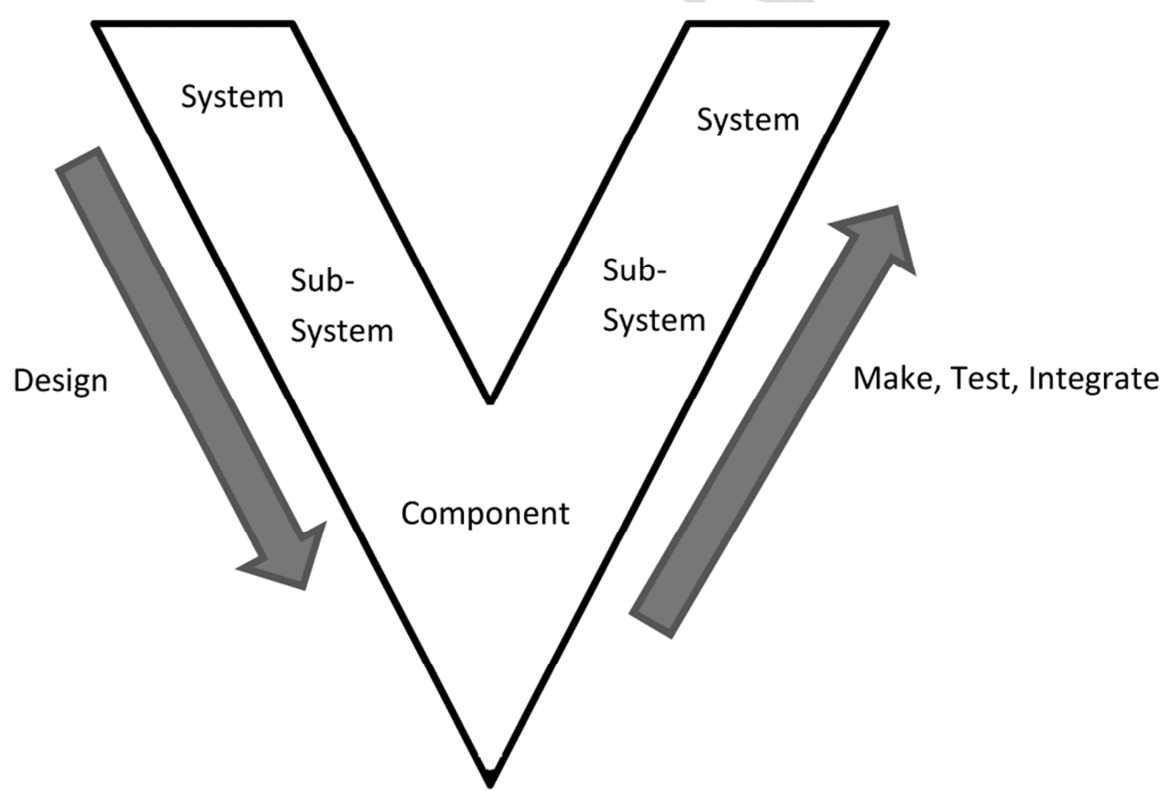

Figure 2 - The classic 3 stage design synthesis diagram from systems engineering. 

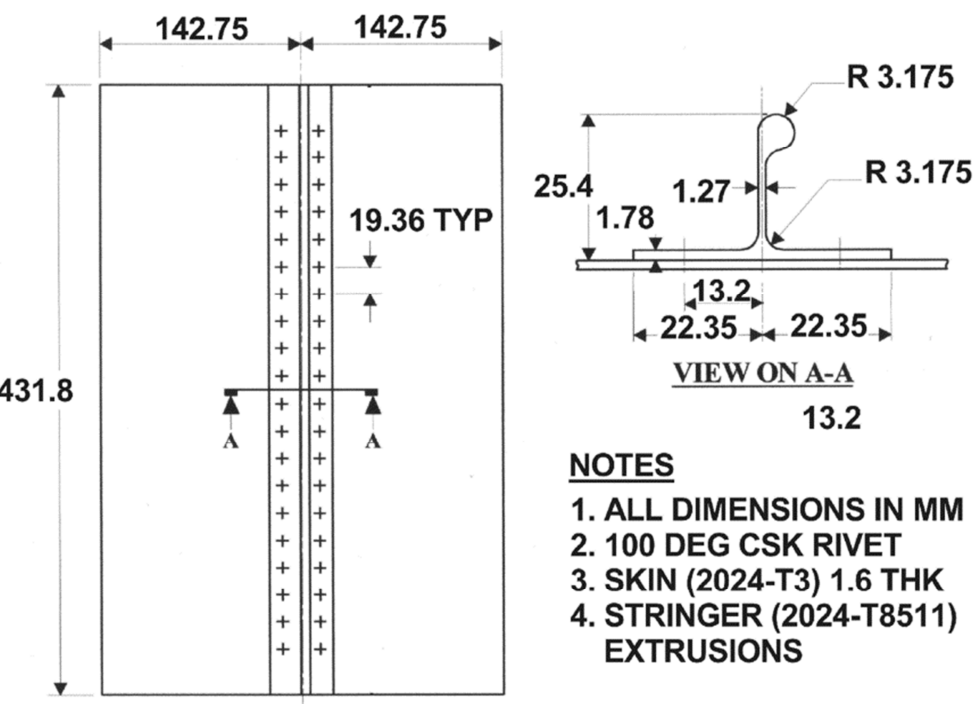

1. ALL DIMENSIONS IN MM

2. 100 DEG CSK RIVET

3. SKIN (2024-T3) 1.6 THK

4. STRINGER (2024-T8511) EXTRUSIONS

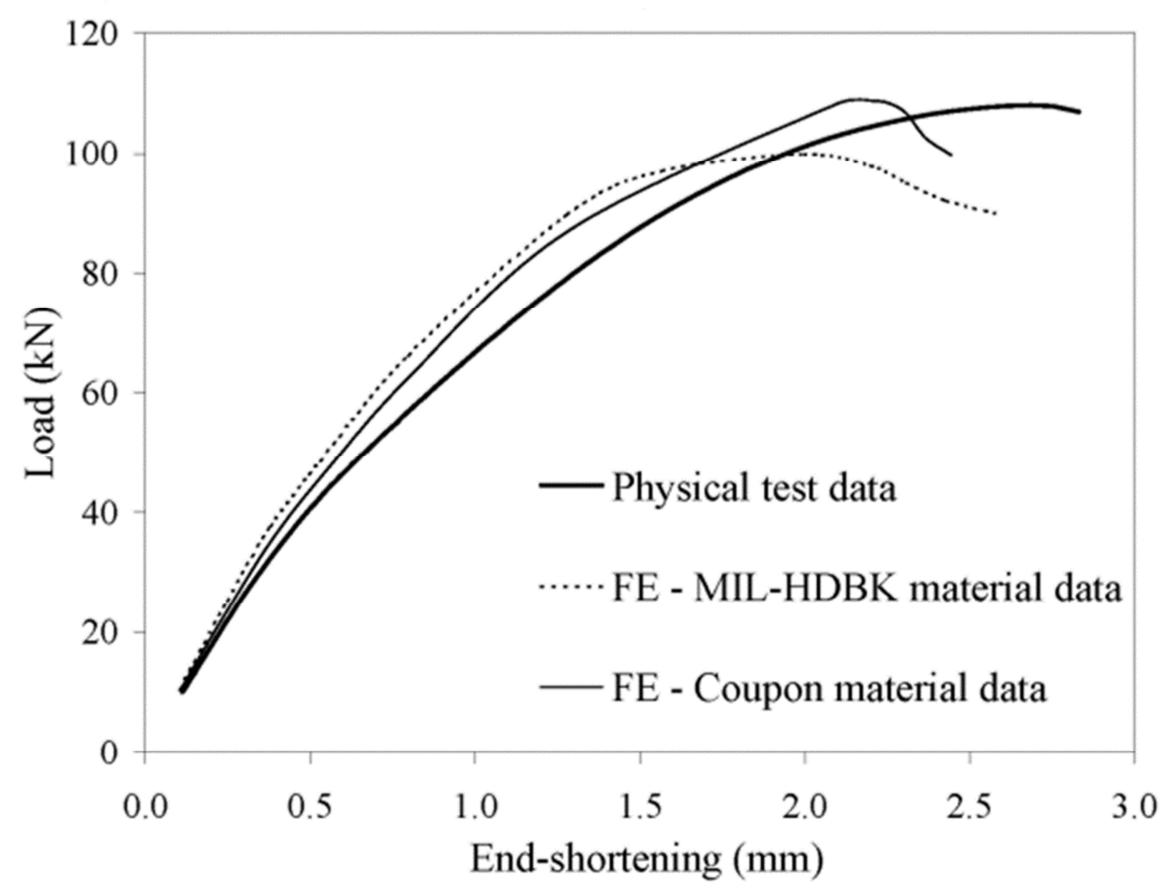

Figure 3 - Measured and predicted stiffness and strength for a riveted specimen consisting of a $0.286 \times 0.432 \mathrm{~m}$ flat skin, stiffened by a single bulb-tee extruded stiffener. 

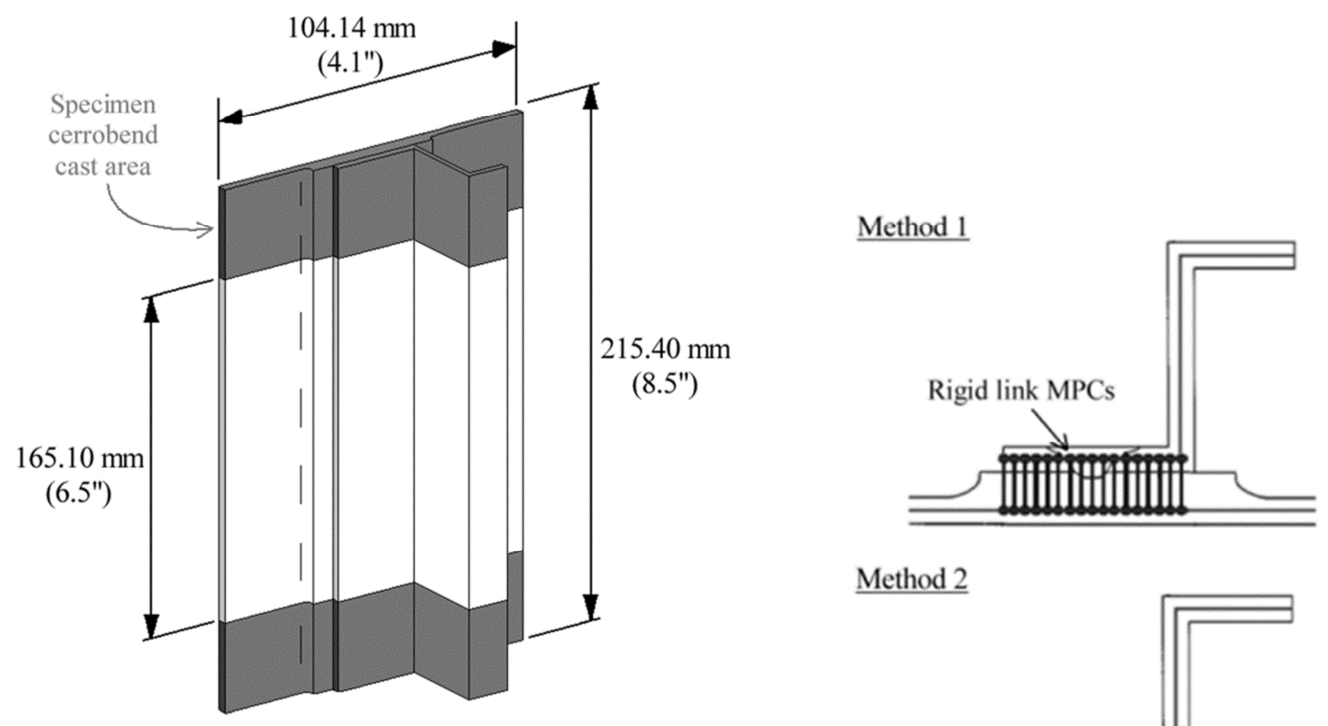

Method 2
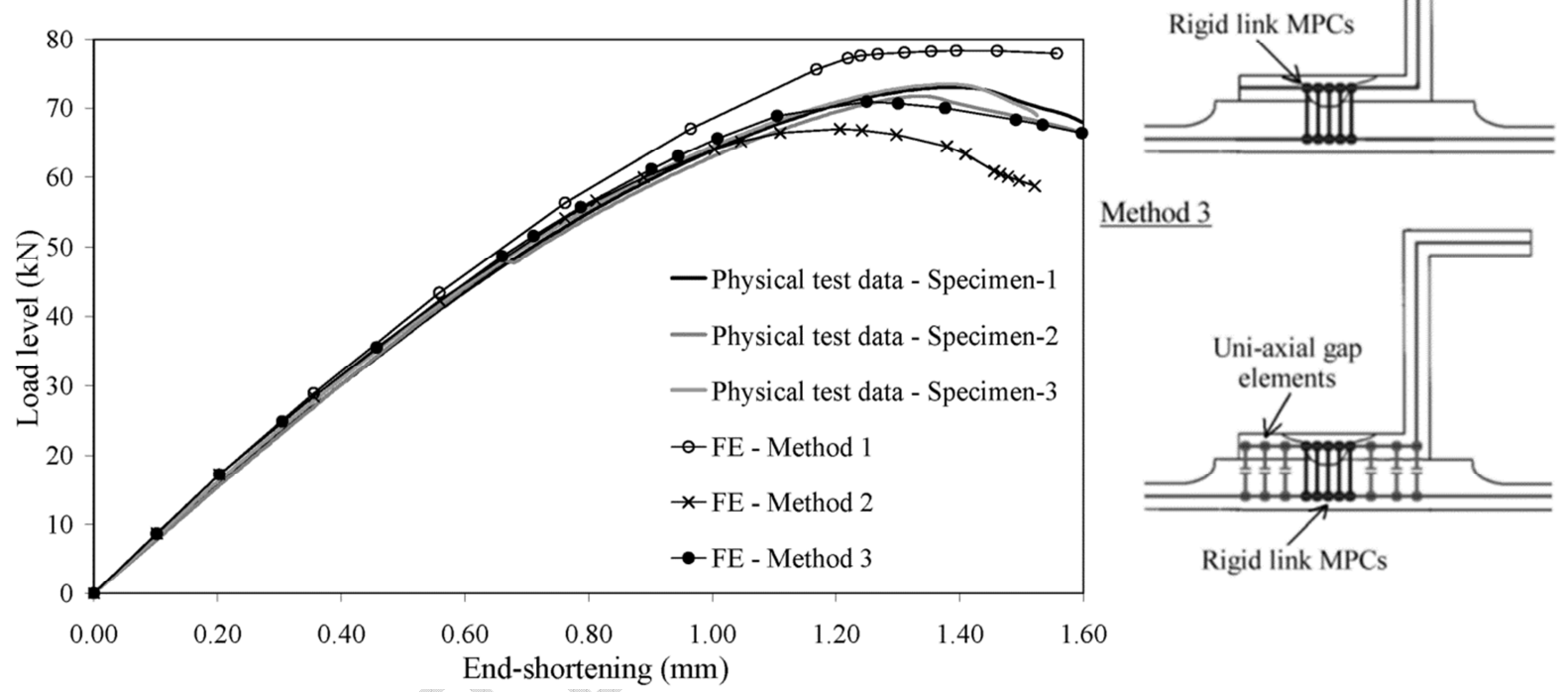

Method 3

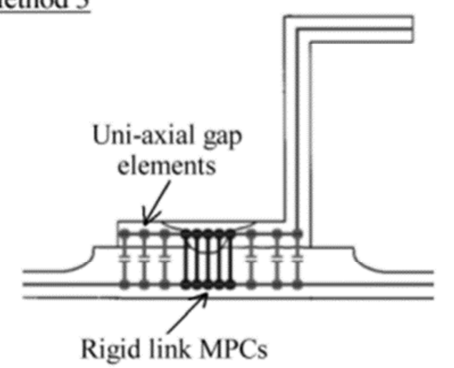

Figure 4-Measured and predicted stiffness and strength for a welded specimen consisting of a flat skin, stiffened by a single Z-section extruded stiffener, plus FE joint idealisations. 


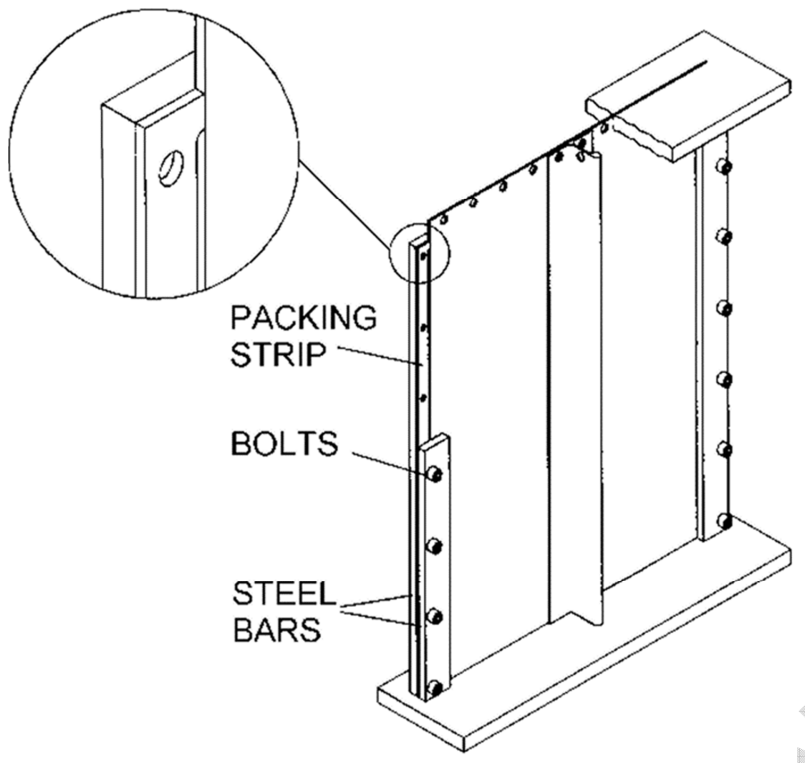

Figure 5 - Experimental edge support design. 


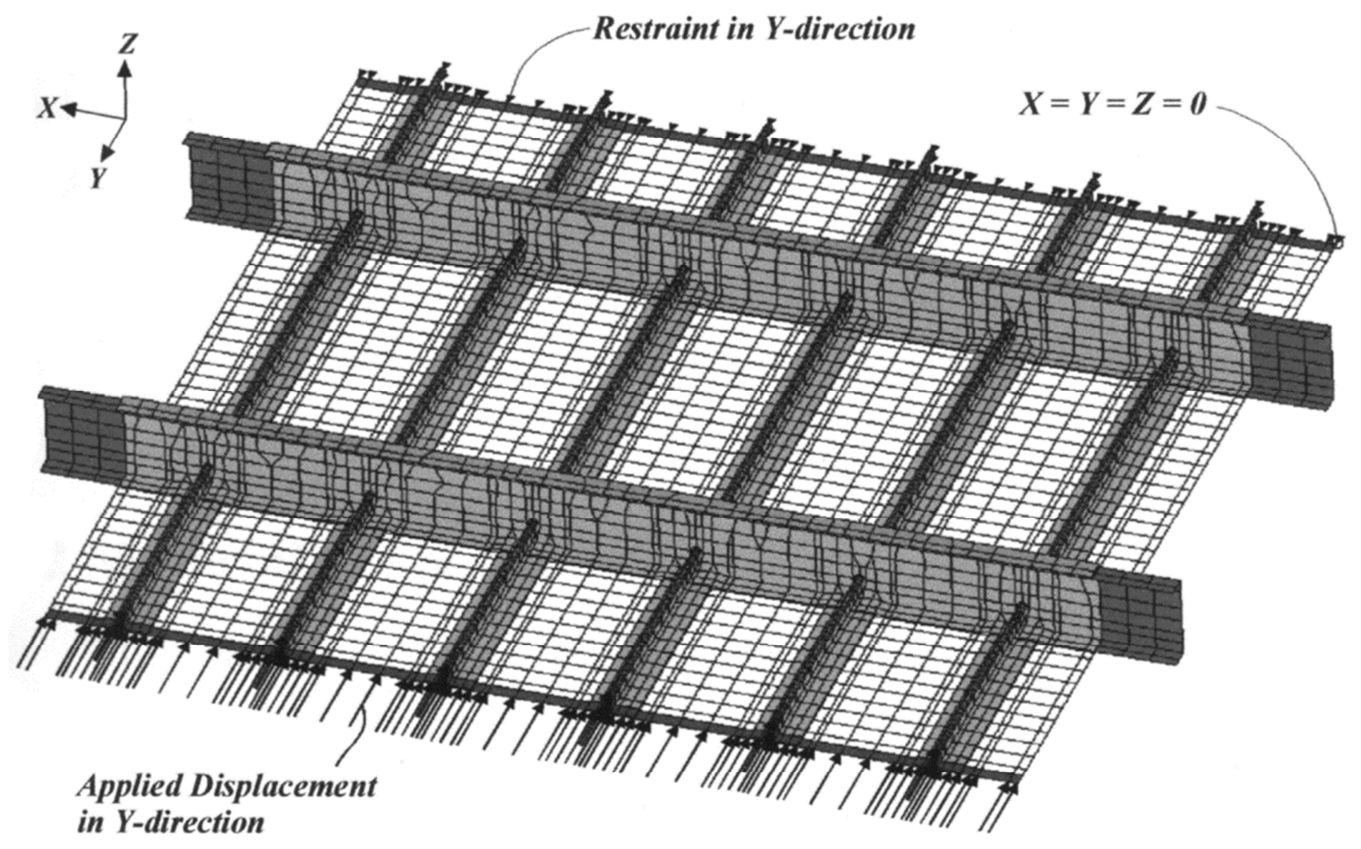

in Y-direction

Stringers

Frame Segments

Frame Segment

Reinforcement Angles

Elements representing material cast within

Cerrobend ( $X$ and $Z$ translations restrained)

Elements representing material contrained by frame

support trolleys ( $Z$ translation and $X$ rotation restrained)

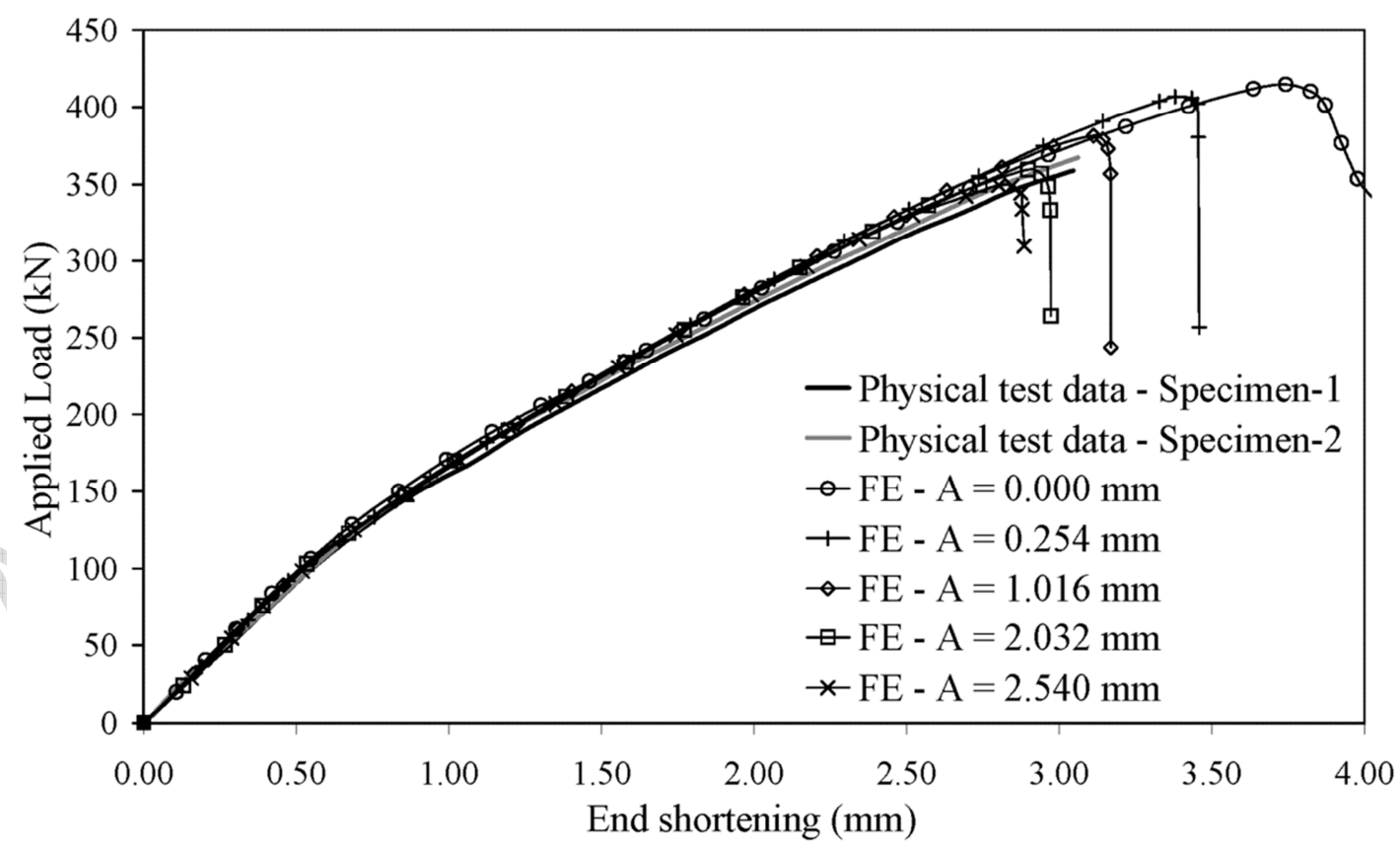

Figure 6 - Measured and predicted stiffness and strength data for a riveted specimen, consisting of a 0.914 by $0.864 \mathrm{~m}$ skin, stiffened by six stringers and two frame segments. 

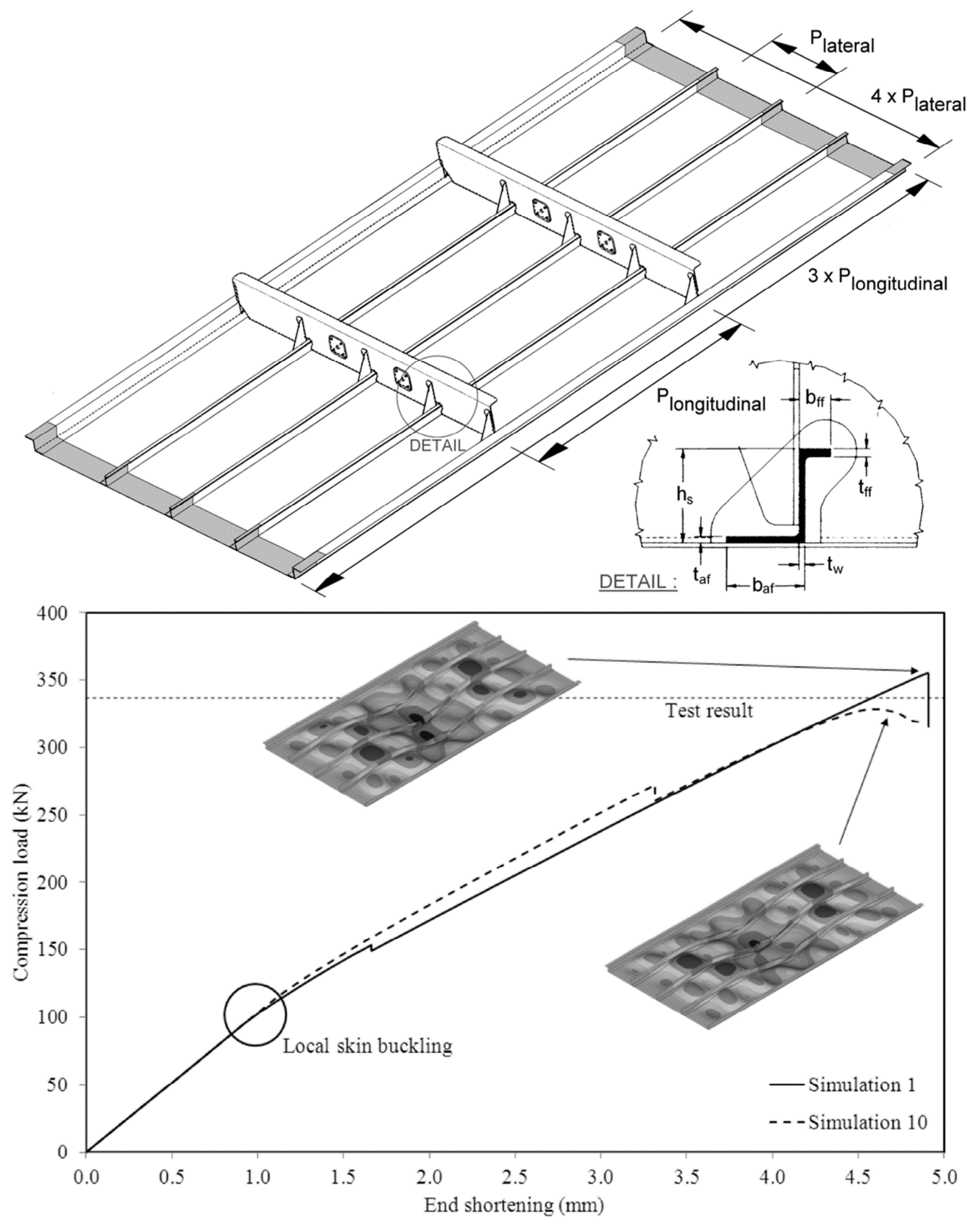

Figure 7 - Measured and predicted stiffness and strength data for a friction stir welded multi stiffener specimen consisting of five Z-section longitudinal stringers and a flat skin. 


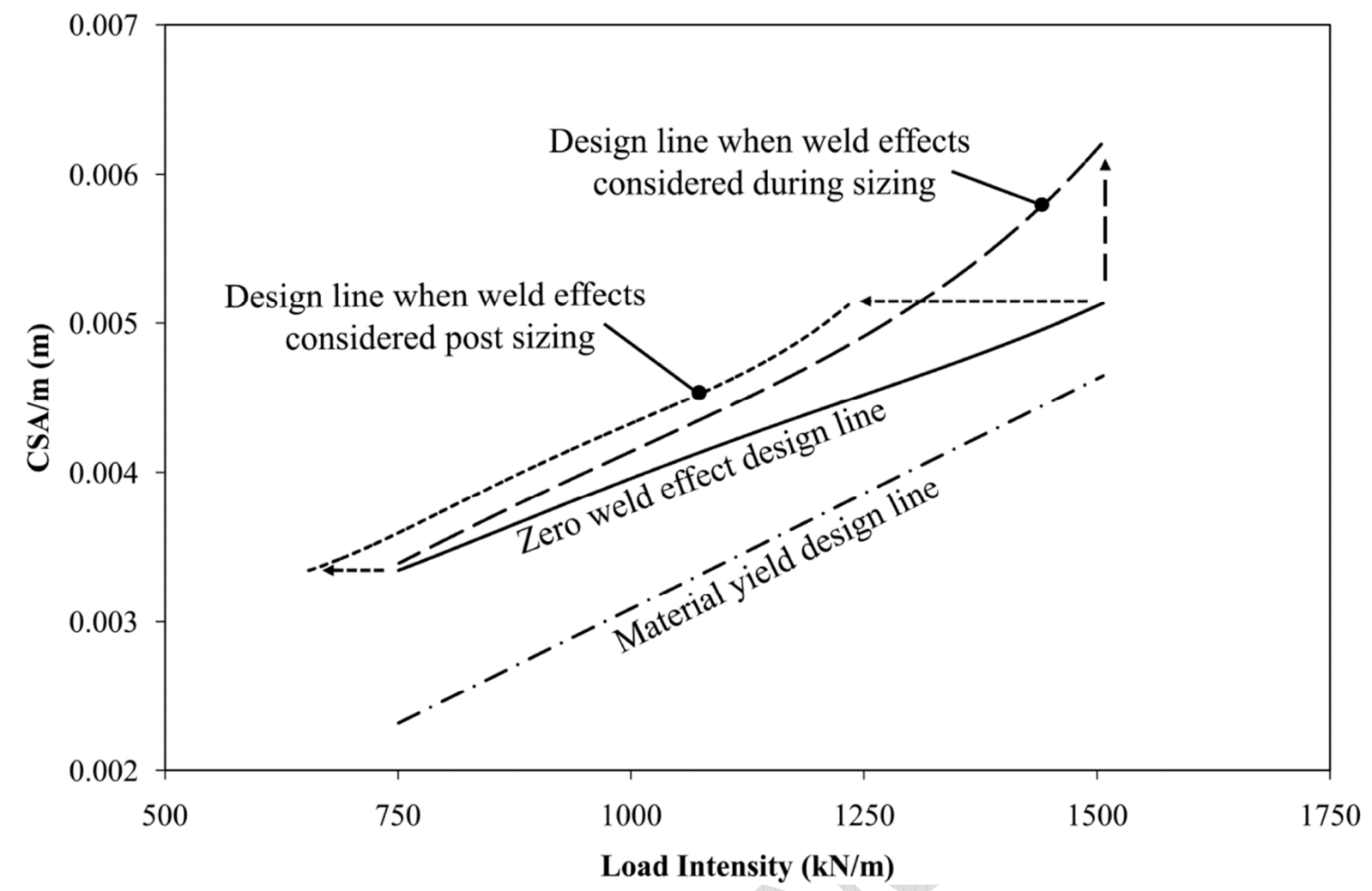

Figure 8 - Initial design study results for a laser beam welded stiffened panel segment - strength per unit width versus cross-sectional area per unit width, results considering design with and without weld effects. 


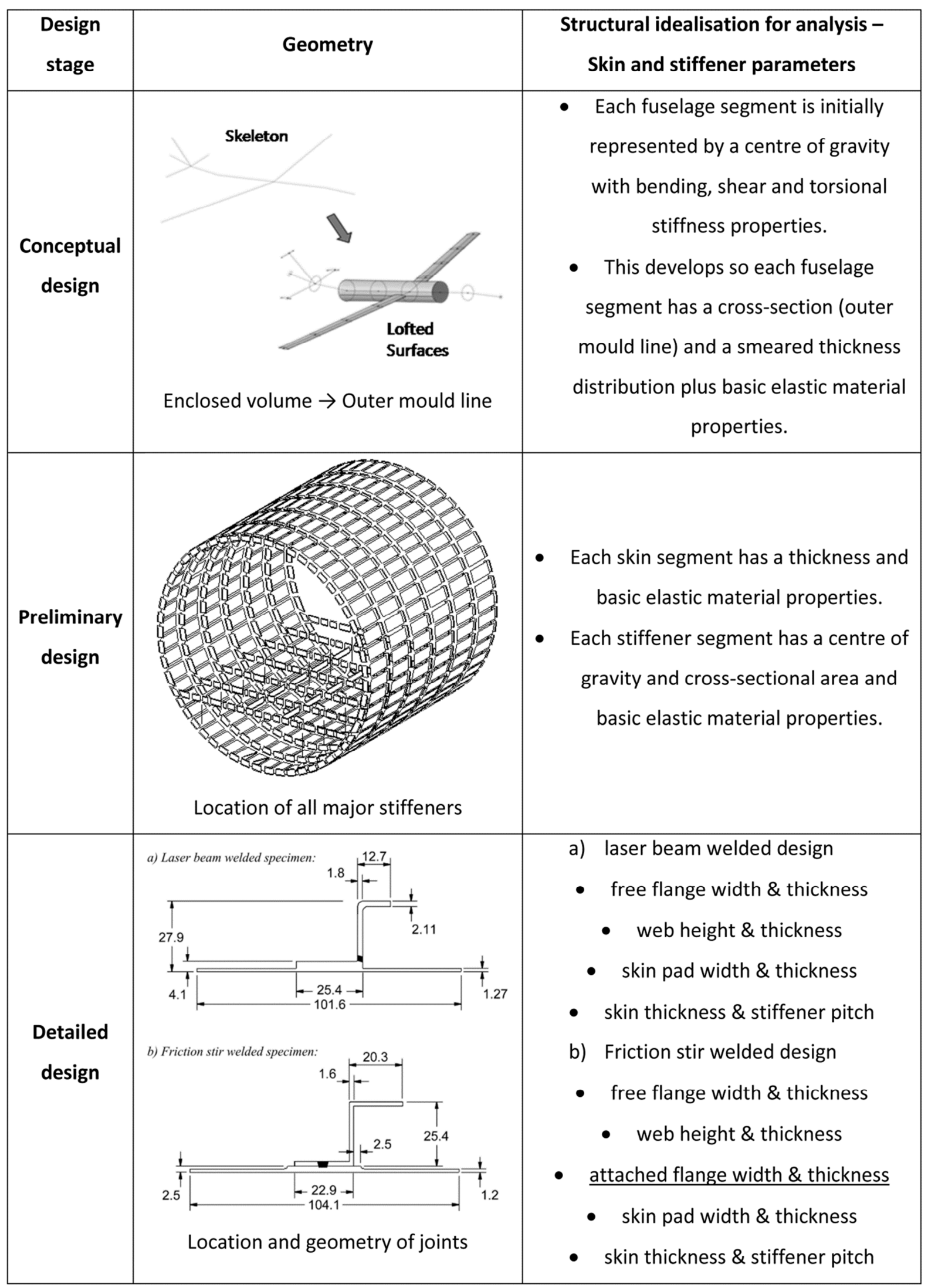

Figure 9 - Design parameter evolution for an aircraft fuselage structure, conceptual, preliminary and detailed design. 

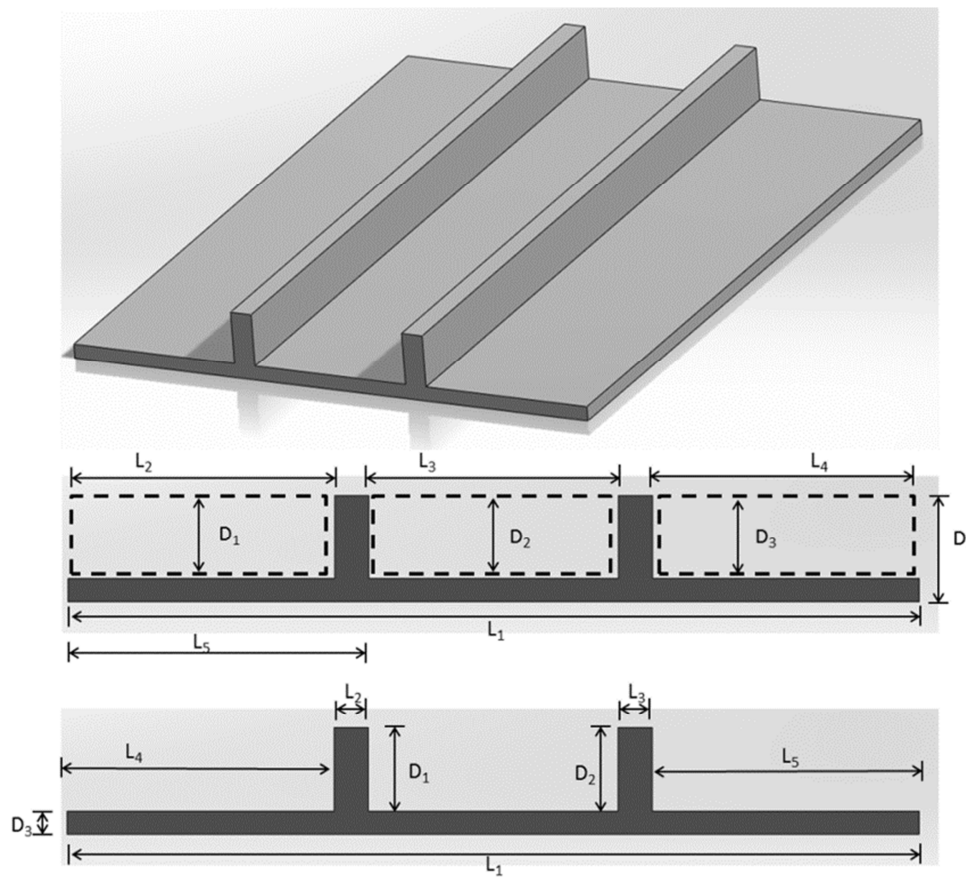

Figure 10 - Parameterisation of a stiffened panel.

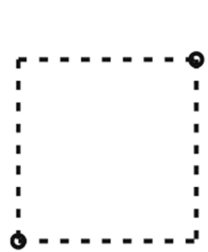

(a)

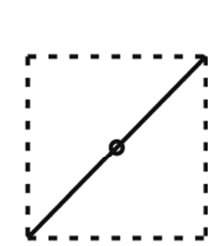

(b)

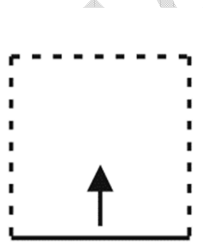

(c)

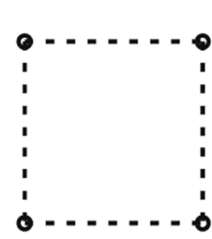

(d)

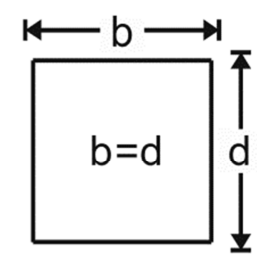

(e)

Figure 11 - Defining a square using different parameterisations. 


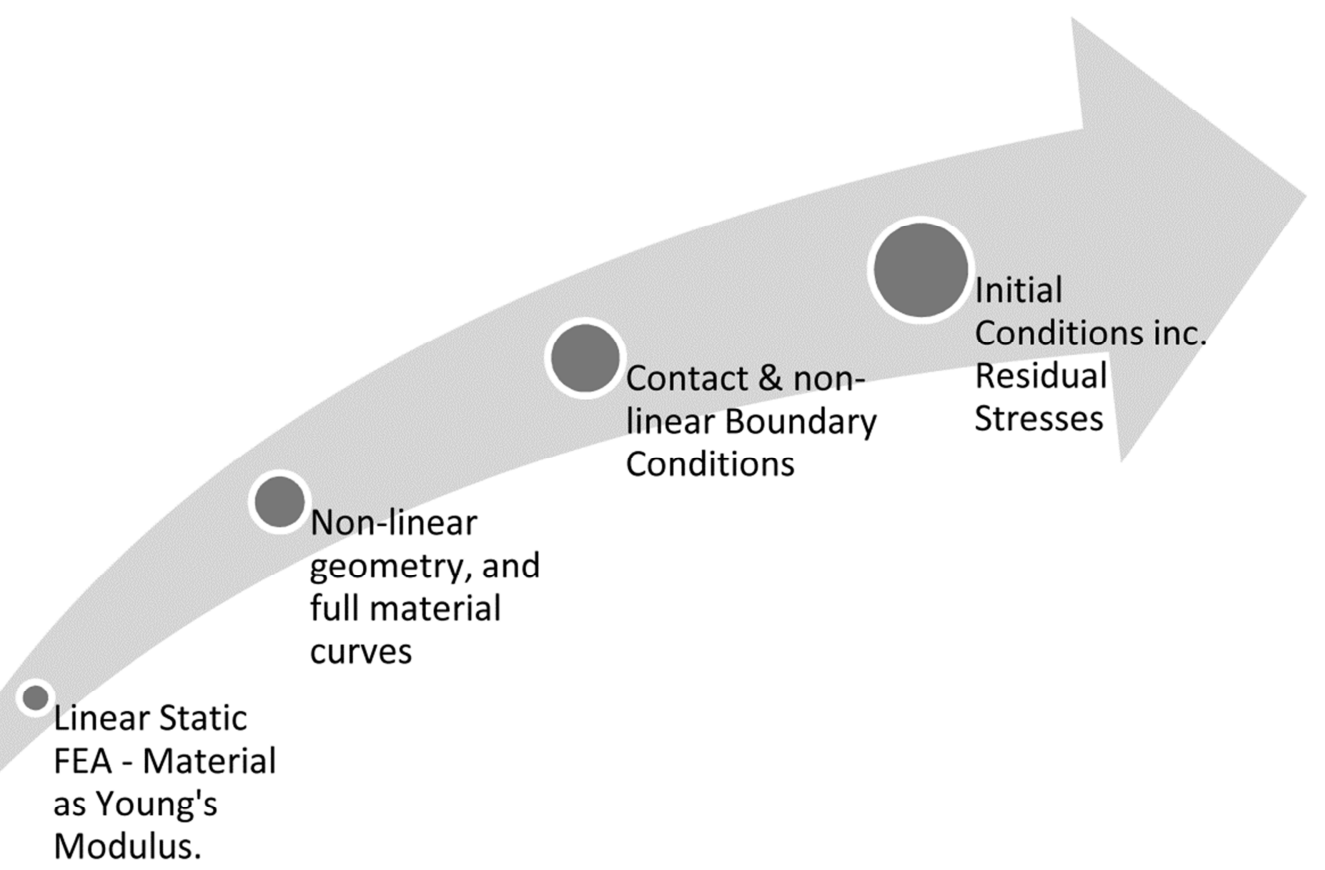

Figure 12: Timeline showing development of computational capability. 